\title{
Das Conseqüências da Falta de Coordenação e Contrôle na Administração de Material
}

\author{
Maria ANTONieta NOgueira Ribeiro
}

\begin{abstract}
Todos aquêles que se preocupam sèriamente com o problema da eficiência dos serviços públicos e se dedicam ao estudo do assunto conhecem a importância da utilização de métodos racionais na administração pública.
\end{abstract}

Essa importância avulta no Estado moderno, dada a sua expansão crescente, a exigir administração eficaz e, conseqüentemente, a proscrição do empirismo, fonte de desperdício e ineficiência.

Essse imperativo de eficiência se apresenta com mais rigor nos jovens países subdesenvolvidos - entre os quais o Brasil - com um patrimônio em formação e com problemas de tôda sorte pendentes de solução (exigüidade de vias de comunicação, de instrumentabilidade educacional etc.), (1) pois que, como salienta o economista HANS W. Singer, os planos de desenvolvimento, mesmo bons, podem ficar prejudicados por deficiência de administração. (2)

Não se justifica, pois, que o Ministério da Fazenda - verdadeiro Ministério da Economia -, departamento a que cabe enorme responsabilidade no desenvolvimento econômico do país, inclusive através do contrôle da pressão inflacionária, condição sine qua non para o êxito dos planos de desenvolvimento, permaneça impermeável a inovações estruturais e dinâmicas, ditadas pelas modernas técnicas administrativas. (3)

Essa possivelmente uma das causas da "inação atarefadíssima" a que são forçados os Ministros da Fazenda... (4)

Indice dêsse alheamento às conquistas no setor do aperfeiçoamento das práticas administrativas encontramos na permanência, por mais de 10 anos,

(1) Benedicto Silva, Assistência Técnica em Administração Pública - Cadernos de Administração Pública editados pela Escola Brasileira de Administração Pública da Fund’ação Getúlio Vargas (n. ${ }^{\circ} 21$ ).

(2) Papel Essencial da Administração Pública no Desenvolvimento Econômico Cadernos citados, n. ${ }^{\circ} 21$, p. 27.

(3) M. A. Teixeira de Freitas, A reforma Administrativa Brasileira e Fenelon DA SILva, Da Reforma e Coordenação dos Meios na Administração, in Revista do Serviço. Público - maio de 1953. e 121.

(4) José MARIa Whitaker, Seis msises, de novo, no Ministério da Fazenda, p. 77 
da situação anômala criada com a expedição do D.L. 8.323-A, de 7-12-45, com grave repercussão sôbre tôda a administração de material no serviço público civil federal.

Antes, porém, de prosseguir, faz-se conveniente um exame retrospectivo.

\section{HISTÓRICO DA ADMINISTRAÇÃO DO MATERIAL NO SERVIÇO PÚBLICO CIVIL FEDERAL}

No estudo da evolução da administração de material no Brasil, na esfera administrativa federal, podemos distinguir 4 períodos:

$1^{\circ}$ ) o anterior à vigência do Código de Contabilidade Pública (D. 4.536, de 28-1-1922);

2. ${ }^{\circ}$ ) o compreendido entre essa data e a criação da Comissão Central de Compras (D. 19.587, de 14-1-31);

$\left.3 .^{\circ}\right)$ o que abrange fase que se inicia aí e termina com a transferência da Divisão do Material do D.A.S.P. e do Conselho de Administração de Material para o Departamento Federal de Compras (D.L. 8.323-A, de 7-12-1945); e

4. ) o que vem daí até os nossos dias.

1. Período - Até a vigência do Código de Contabilidade Pública, a administração de material estava entregue às próprias repartições, que se regulavam por disposições esparsas - contidas freqüentemente nas leis orçamentárias - (1) com uma contabilidade incipiente, instável e desordenada, enfeixando os respectivos dirigentes em suas mãos, tôdas as atribuições, desde a aquisição do material até sua alienação por cessão ou venda.

2..$^{\circ}$ Período - Com o Código de Contabilidade e o seu regulamento, aprovado pelo D. 15.783, de 8-11-1922 e pela Lei 4.632, de 6-1-1923 (Art. 162), a aquisição, o abastecimento e a aplicação continuaram a ser descentralizados, já aí, entretanto, sob um contrôle mais ativo do Tribunal de Contas, que, criado desde 1890, encontrara na desordem contábil obstáculo ao exercício de suas atribuições. (2)

A inclusão no referido Código de disposições gerais destinadas à fiscalização sôbre o material foi inspirada no exemplo da Itália, que dava cuidadosa regulamentação a essa matéria, pois que, já em 1874, através de comissão encarregada de promover melhoramentos na contabilidade pública daquele país, verificara a importância da fiscalização sôbre os armazens e depósitos pertencentes ao Estado, como garantia dos interêsses nacionais, dado o valor considerável de seus bens.

Tcdavia, dificuldades de tôda ordem - inclusive a reação daqueles que queriam ver-se livres do contrôle a que ficaram sujeitos - impediram que a

(1) Entre outras: D. 2.926, de 14-5-1862; Lei 2.221, de 30-12-1909; Lei 3.232, de 5-1-1917 (Art. 94 etc.); Lei 3.454, de 6-1-1918 (Art. 170 etc.); Lei 3.991, de 5-1-1920 (Art. 73 etc).

(2) A. BiolchinI, Codificação da Contabilidade Pública Brasileira $-10^{\circ}$ volume, pp. $243,535 / 537$. 
fiscalização financeira se fizesse com eficiência, ensejando mesmo que se transformasse freqüentemente em entrave à boa marcha dos trabalhos e em motivo para tôda sorte de fraudes, bem ou mal intencionadas: "química" orçamentária, "balões de ensaio" etc.

3. Período - Êste é o período áureo da administração de material no serviço público federal; seu exame requer, por isso mesmo, a divisão do assunto em subtítulos.

3. Período - Sistematização da administração Pública - Segundo o Prof. PEDRo MUÑoz AMato, (1) foi a partir do último têrço do século XIX que a sistematização da administração pública entrou em fase de desenvolvimento sem precedentes, sendo as causas primárias do auge alcançado por êsse desenvolvimento as transformações radicais da cultura ocidental naquele século (o apogeu da ciência, a revolução industrial, o desenvolvimento prático do ideal democrático do estabelecimento do contrôle do povo sôbre o govêrno e a revolução socialista).

Nos Estados Unidos, êsse movimento de administração racional ganhou impulso em princípios dêste século com os ensinamentos de FrEDERIK W. TAYLOR, (2) sendo êsse país atualmente o que possui mais desenvolvida literatura sôbre a teoria geral da administração pública, cujos rumos foram traçados, já em 1887, por Woodrow Wilson. (3)

No Brasil, aquêle movimento manifestou-se sòmente após a revolução de 1930, quando se empreendeu a reorganização administrativa federal adotando-se métodos racionais e critérios científicos, numa verdadeira "Corrida da Eficiência".

Levou-se em conta nessa reorganização a clássica divisão das atividades do govêrno: atividades fins, também chamadas substantivas, primárias, funcionais, específicas, especiais, principais ou finais e atividades meios ou gerais, ainda denominada adjetivas, institucionais, domésticas ou auxiliares.

As primeiras são aquelas que constituem a própria razão de ser do órgão criado, as que os governos exercem para realizar os objetivos do Estado (defesa nacional, segurança pública, educação, proteção à saúde etc.); as atividades adjetivas ou institucionais são aquelas que equipam o govêrno para funcionar e subdividem-se em 2 grupos: a) serviços auxiliares e $b$ ) serviços de estadomaior. (4)

Os serviços auxiliares - predominantemente executivos - compreendem os recursos humanos e físicos utilizados pelos governos para pôr e manter seus órgãos em funcionamento, sendo os mais importantes: pessoal, material, dinheiro, documentação, edifícios e instalações.

Os serviços de estado-maior (pesquisa, previsão, planejamento, preparação de informação e, em geral, assessoramento) têm por objetivo, principalmente, facilitar a ação dos administradores.

(1) Introdução à Teoria Geral da Administração Pública - Cadernos citados, n. ${ }^{\circ} 23$.

(2) Princípios de Administração Científica - Tradução de ARLindo VieIra Ramos.

(3) O Estudo da Administração - Cadernos citados, n. 16.

(4) Benedicto Silva, Op. cit. 
Um dos propósitos da sistematização da administração pública é, assim, criar condições que libertem as chefias executivas de preocupações com as tarefas rotineiras, para que possam devotar maior tempo e energia à realização de suas atividades específicas.

Cuidou, pois, o Govêrno Provisório da racionalização das atividades de administração geral, manifestando-se desde logo no setor do material o esfôrço para aperfeiçoar os métodos de trabalho, o que vem comprovar a importância dêsse elemento no serviço público.

Comissão de Padrões - Com o D. 19.512, de 20-12-1930, criou-se a COMISSÃo DE PADRõEs, encarregada de estabelecer os padrões que seriam adctados nos fornecimentos de materiais necessários à execução dos serviços do Govêrno Federal.

Poucos dias após (D. 19.549, de 30-12-1930), o Chefe do Govêrno Provisório, impressionado com o vulto da despesa nos orçamentos anteriores, suspende as exigências contidas nos arts. 244, 736, 738 e 764, do Código de Contabilidade da União, relativamente à celebração de concorrências e contratos para a aquisição de material ou execução de serviços em proveito das dependências da União.

Fundamentou-se o ato na conveniência de evitar a celebração de contratos às vésperas de modificação do regime de fornecimentos - então em estudo, para adoção de novo critério no menor prazo possível - e na verificação de que a exigência de concorrências públicas e contratos para a realização de serviços acarretava, em muitos casos, graves inconvenientes, sem importar nem em redução das despesas correspondentes, nem na bôa execução dos serviços contratados.

Regulamentou-se então o novo processo de aquisição, prevendo-se o registro da despesa pelo Tribunal de Contas "a posteriori", o qual não poderia ser recusado no caso de se julgar excessivo o valor global de qualquer dos fornecimentos; nesta circunstância, o Ministério competente promoveria a responsabilidade do funcionário que tivesse autorizado o fornecimento, obrigando-o a indenizar o Estado da importância do excesso apurado.

Os estudos feitos levaram, porém, o Govêrno à constatação da conveniência da centralização das compras em um só órgão, criando-se a CoMissão CENTRAL DE CoMpras (D. 19.587, de 14-1-31), imediatamente subordinada ao Ministro da Fazenda, encarregada, com exclusividade, da aquisição de todo e qualquer material e de seu fornecimento ao serviço público federal.

A Comissão de Padrões, que seria designada pelo Ministério da Fazenda, foi absolvida pela C.C.C., passando a funcionar junto à sua secção técnica.

Centralização das Compras - A questão da centralização das compras de material tem sido objeto de estudo por parte daqueles que se preocupam com a racionalização da administração pública.

Os argumentos favoráveis à centralização são relevantes, sendo o mais saliente o que ressalta a economia que proporciona êsse sistema, principalmente nas compras em larga escala. 
Entre as causas da redução do custo direto ou indireto do material adquirido por êsse método, apresentam-se as seguintes: (5)

I - A centralização possibilita o aumento do volume de cada compra e a conseqüente diminuição do número de aquisições:

a) pela simplificação do material, que diminui o número de suas variedades e tipos; pela especificação, que permite a descrição precisa e completa do material desejado; e pela padronização, que torna obrigatória a adoção de determinados tipos em tôdas as repartições;

b) pela reunião dos pedidos dos diversos órgãos, facilitada pelo Calendário de Compras; e

c) pela compra em maior quantidade para armazenagem e distribuição nas épocas oportunas.

II - A especificação, determinando com precisão o material desejado, dificulta, através da inspeção, a fraude na entrega, tal como fornecimento de material inferior ao adquirido etc.

III - A padronização oferece condições ao fabricante para produção em maior quantidade, o que redunda em diminuição do custo.

IV - A redução do número de pedidos (6) acarreta economia substancial na administração já que:

a) propicia a redução do pessoal;

b) permite maior especialização dos servidores, dada a diminuição das tarefas rotineiras, o que os torna capazes de um estudo mais apurado dos mercaddos, internos ou externos, para aquisições mais vantajosas, nas melhores fontes e nas melhores épocas.

$\mathrm{V}$ - A instalação de armazéns centrais, em lugar de um número considerável de almoxarifados distribuídos pelas diversas repartições, permite maior vigilância etc.

A centralização oferece ainda outras vantagens:

a) permite, no caso de materiais escassos, distribuição segundo critério de prevalência da prioridade para a repartição mais necessitada;

b) fornece condições excepcionais para a colheita de dados estatísticos, inclusive de custo e para a pesquisa de informações sôbre o crédito e a idoneidade das firmas concorrentes;

c) torna as concorrências acessíveis a todos os fornecedores - dandolhes "igualdade de oportunidade", exigência democrática - o que traz, aliás, a redução dos preços e constitui maior dificuldade às combinações entre fornecedores;

(5) John R. Simpson, Centralização de Compras para o Serviço Público, Cadernos citados n. ${ }^{\circ} 14$, e Fernando MeIrelles de Miranda, A Compra Centralizada.

(6) A Comissão HOOver, nos Estados Unidos, constatou que a metade aproximadamente dos milhões de pedidos anuais era de 10 dólares no máximo e que o custo administrativo da operação de compra era superior ao preço do material. - JOHN R. Simpson op. cit. 
d) permite transferência de material entre repartições (cessões, por empréstimo ou definitivas, ou permutas) e reunião de material inservível para alienação em condições mais vantajosas;

e) liberta os administradores de preocupações com essa atividade meramente auxiliar, permitindo-lhes aplicar tôda sua atenção e energia em suas tarefas essenciais, etc.

As desvantagens da centralização recaem antes sôbre o seu funcionamento que pròpriamente sôbre o sistema e são passivis de correção, sendo os principais argumentos contrários os seguintes:

a) o órgão comprador não oferece um serviço tão eficiente quanto o que a repartição interessada poderia oferecer a si própria;

b) o material fornecido nem sempre corresponde exatamente ao desejado, prejudicando a eficiência do serviço;

c) há, por vêzes, excesso de padronização, determinando modificações dispendiosas nos métodos de trabalho;

d) propicia atrasos no fornecimento de material urgente e complicações na reforma e cancelamento dos pedidos, com prejuízos enormes em têrmos de economia e eficiência;

e) há elevação do custo da contabilidade, múltipla;

f) a padronização constitui impecilho para o aparecimento de idéias originais em matéria de produção; tiva;

g) o emperramento do sistema prejuidica tôda a máquina administra-

h) propicia complicada rotina de papéis e a formação de um exército de servidores para tarefas complementares; etc.

i) no caso de órgão afastado da capital, há perda do prestígio local

No confronto entre vantagens e desvantagens verifica-se que as razões favoráveis à centralização são de maior relevância e que as ponderações contrárias se dirigem quase que exclusivamente a conseqüências do mau funcionamento do sistema.

São, pois, falhas que podem ser afastadas mediante uma vigilância constante, exercida através de órgãos próprios de contrôle e supervisão.

Criação da Comissão Central de Compras - Segundo adverte JoHn R. SimpSon, (7) a implantação do sistema de centralização das compras - cujo êxito depende de firme decisão governamental, apoiada em legislação adequada - deve ser precedida de cuidadoso estudo; antes, pois, da criação do órgão central de compras é necessário um levantamento censitário, por classe de material, para que se conheçam quais os materiais que são comprados com regularidade pelas diversas repartições, bem como o volume de suas compras.

Ta1 não se fêz antes da criação da Comissão Central de Compras, o que criou sérias dificuldades ao seu funcionamento.

(7) Op. cit. 
Imediatamente subordinada ao Ministro da Fazenda, cabia-1he, com exclusividade, a aquisição e o fornecimento de todo e qualquer material necessário aos serviços públicos.

Criada a título experimental, para transformação oportuna em órgão estável com a organização que a prática aconselhasse, (8) com jurisdição sôbre todo o território nacional - prevista a criação de agências nos Estados quando necessário - essa Comissão sofreu tôda a sorte de resistências.

O Ministério da Guerra jamais se submeteu à sua autoridade, sendo seguido nessa atitude pela Polícia Militar do Distrito Federal, pelo Corpo de Bombeiros e mais tarde pelo Ministério da Marinha.

Além da falta de planejamento, foram óbices ao bom funcionamento daquela Comissão: a campanha movida pelos que se viram privados do direito de comprar diretamente e que se valeram, para obstrução dos trabalhos, até mesmo do recurso da sabotagem; a reação dos fornecedores "donos das repartições", prejudicados em seus interêsses; o ambiente post-revolucionário, a propiciar críticas dos descontentes; a falta de apôio firme do govêrno que, por vêzes, cogitou de extinguí-la; (9) e os conflitos entre a legislação própria e o Código de Contabilidade Pública, com as conseqüêntes recusas de registro pelo Tribunal de Contas.

Uma das inovações mais combatidas à época - a escolha da oferta que menos ônus acarretasse para o Tesouro (art. $8 .^{\circ}, \S 12$, do D. 19.587-31) e não o menor preço como o exigia o Código de Contabilidade Pública - foi mantida posteriormente, através do art. 24 do D.L. 2.206-40, o que evidencla a improcedência das críticas então formuladas.

Assim, só a vontade férrea daqueles que queriam desimcumbir-se a contento da responsabilidade assumida impediu o fracasso da iniciativa. (10).

$\mathrm{E}$ foi por êsse motivo - aliado às facilidades legais proporcionadas que, apesar de tôdas as dificuldades que the foram opostas deliberadamente, a C.C.C. apresentou apreciáveis resultados nos 3 primeiros anos, havendo abastecido as repartições de todo o material requisitado, por mais variado que fôsse, e recolhido ao Tesouro saldos não aplicados no valor de $\mathrm{Cr}$ \$ $120.000 .000,00$, sendo que mais de $\operatorname{Cr} \$ 54.000 .000,00$ referentes ao primeiro ano.

O regime que se pretendeu estabelecer para o funcionamento da C.C.C., visando à simplificação do processo de compras, era o do registro "a posteriori", o que foi dificultado com a exigência de registro prévio dos contratos, consagrado pela Constituição de 1934 .

O confronto realizado em 1933 entre os preços de municiamento de bôca, tomados por base os dados da C.C.C. e do Ministério da Marinha, evidenciou

(8) Apostilhas do Prof. Oscar VICTORINo MOREIRA, do Curso de Administração e Legislação de Material dos Cursos de Administração do DASP. - Ponto n. ${ }^{0} .2$ pp. 7 .

(9) OsCar Victorino Moreira, Redução do Custo dos Serviços do Material, pp. $8 \mathrm{~S}$ in fine.

(10) OSCAR VICTORINO MOREIRA, Op. cit. 
a favor da centralização das aquisições uma redução de $40 \%$ aproximadamente. (11).

Outras economias que se devem à centralização, à época:

Aquisições de papel $\ldots \ldots \ldots \ldots \ldots \ldots \ldots \ldots \ldots$

$33,9 \%$

Tecidos e seus produtos manufaturado $\ldots \ldots \ldots \ldots \ldots$.

$55 \%$

Trilhos para a E. F. Noroeste ............... $20 \%$

Motores Diesel para a E. F. Central do R. G. Norte .. $15 \%$

Além dêsses resultados favoráveis, iniciou a C.C.C. os estudos de especificação de material, tentou uma classificação decimal para os materiais e forneceu elementos estatísticos para a orientação no conhecimento do material que se adquiria. (12)

Mas o maior mérito que se pode atribuir àquela Comissão é - como já se tem afirmado - o de haver sido a pioneira no desbravamento do caminho para a instalação do sistema de administração de material.

Com a reorganização promovida com o D. 24.036, de 26-3-34, o órgão central de compras foi incluído entre as repartições auxiliares e dependentes do Tesouro Nacional (13), cabendo ao Ministério da Fazenda dirigir o serviço de compra do material, promover sua distribuição, e estabelecer, com o concurso de técnicos dos diversos Ministérios, sua padronização (Art. $4 .{ }^{\circ}$, II, alínea i), bem como examinar a oportunidade de encomendas de materiais no estrangeiro, por qualquer Ministério, ainda quando houvesse crédito consignado para o respectivo custeio (Art. 8..$^{\circ}$, alínea f).

Comissão Permanente de Padronização - Com o D. 562, de 31-12-35, é criada essa Comissão, diretamente subordinada ao Presidente da República, encarregada de simplificar e padronizar o material de uso comum no serviço público civil e que realizou trabalho notável no terreno dos papéis oficiais, o que constituiu por sua vez elemento importante para a padronização das máquinas dactilográficas, dos móveis de escritório e mesmo da tinta de escrever.

Convém lembrar que, segundo esclarece Eudoro L. BERLINCK, (14) só no Ministério do Trabalho havia 419 tipos de envelopes; que com relação aos timbres, além de 2 emblemas, o globo e a estrêla - de dimensões variadíssimas - havia uma locomotiva fumegante, a Cruz de Malta, as armas da República com a inscrição de data significativa para certa corporação etc., e que variavam os papéis, quanto à qualidade, segundo o gôsto das repartições, encontrando-se de 57 até 110 gramas por metro quadrado.

Departamento Administrativo do Serviço Público - Em 1938 é criado o D.A.S.P. (D.L. 579, de 30-7-38) que, através de sua Divisão do Mate-

(11) Ibidem, p. 94.

(12) Idem - Op. cit.

(13) Arts. 1. ${ }^{\circ}$, alínea $J ; 24, h$ e 188.

(14) A Padronização dos Papéis de Expediente - "Revista do Serviço Público" novembro de 1937. 
rial, absorve as funções da Comissão Permanente da Padronização, que é extinta; atribuiu-se àquele Departamento, além da organização anual da proposta orçamentária e da fiscalização da execução da lei resultante, o estudo pormenorizado das repartições, com o fim de determinar, do ponto de vista da economia e eficiência, as modificações a serem feitas na organização dos serviços públicos, sua distribuição e agrupamento, dotações orçamentárias, condições e processos de trabalho, relação de uns com os outros e com o público.

Segundo Themístocles B. Cavalcanti, (15) já existia sob a Constituição de 1934 tendência para constituir-se junto à Presidência da República um aparelhamento técnico destinado a atender a certos serviços de ordem administrativa, de interêsse geral para todos os Ministérios, daí resultando a criação da citada Comissão Permanente de Padronização e do Conselho Federal do Serviço Público.

O desenvolvimento dêsses órgãos levou à criação do D.A.S.P., cujas funções, constitucionalmente, (16) tinham o caráter auxiliar, consultivo, técnico-administrativo, junto ao Presidente da República, assessorando-o e contribuindo para a coordenação dos serviços afetos aos diferentes Ministérios. (17).

No setor do material, atribuiram-se-lhe funções normativas referentes a orçamento, requisição, especificação, compra, recebimento, guarda, distribuição, troca, cessão, venda, utilização, recuperação e escrituração do material; estudo e proposta de fixação de especificações de materiais para uso nos serviços públicos; coordenação dos trabalhos dos órgãos de material, propondo as medidas necessárias para o seu funcionamento uniforme; estudo, em cooperação com a Divisão de Organização e Coordenação (D.C.) e Serviço de Obras (S.Ob.) e as repartições interessadas, dos projetos de aparelhamento, equi.pamento e instalação de serviços; orientação e fiscalização da parte executiva da administração de material; colaboração com a C. O. do Ministério da Fazenda na elaboração do orçamento, na parte relativa a material etc. (18)

São comprovantes da intensa atividade do D.A.S.P. no referido setor, além de sua participação na expedição dos decretos e decretos-leis dêste $3 .^{\circ}$ período: Instrução n. ${ }^{\circ} 1$, aprovada com a Portaria 197 , de 18-7-1939 (D. O. de 31 ), referente à requisição e recebimento de impressos etc.; E. M. 1908 (D.O. de 19-10-39), que sugere normas sôbre a aquisição de material padronizado; (19) Portaria 2.199, de 7-10-1942 (D.O. de 20), sôbre padronização de carimbos e 186, de 26-6-43, sôbre o mesmo assunto; Portaria 657, de 16-3-44 (D.D. de 18 ), referente ao uso de canetas-tinteiro de propriedade do Estado;

(15) O Departamento Administrativo na Estrutura Ccnstitucional de 10 de novembro - "Rev. do Serviço Público" - agôsto de 1938, p. 49.

(16) Constituição de 1937.

(17) Themístocles Bl Cavalcanti, Op. Cit.

(18) D. 11.101, de 11-9-42, que aprovou seu regiments.

(19) Leia-se a Circular S.P.R. 10/39 (D.O. de 24-10-39). 
Portaria 871 , de 26-7-44 (D.O. de 28 ) sôbre requisição e aceitação de uniformes; E.M. 2.155, de 3-8-44, que deu motivo à Circular S.P.R. n. ${ }^{\circ} 7 / 44$ (D.O. de 25-8-44), sôbre simplificação e padronização etc.

Laboratório de Ensaios e Exames Técnicos - Com o D. L. 1.184, de 1.4-39, atribui o Govêrno ao Instituto Nacional de Tecnologia do Ministério do Trabalho - que será o órgão técnico consultivo da C.C.C. - a execução dos ensaios para especificação e padronização do material destinado aos serviços públicos e os exames técnicos para seu recebimento.

Em conseqüência, o laboratório da Comissão Central de Compras (criado com o D. 19.587-31), embora continuasse a funcionar junto ao órgão comprador, ficou subordinado técnica e administrativamente ao referido Instituto. (20)

Disposições Estatutárias relativas a Material - Com o D.L. 1.713, de 28-10-39 (Estatuto dos Funcionários Públicos Civis da União), decretaram-se medidas destinadas a precaver o Estado contra os prejuízos no setor do material; previu-se entre os deveres dos seus servidores o de zelar pela economia e conservação do material que thes fôr confiado (Art. 224, XIII); exigiu-se a prestação de fiança pelos que tenham sob sua guarda ou responsabilidade quaisquer bens ou valores da União (Art. 30, regulamentado pelo D. 8.738, de 11-2-42); (21) estabeleceu-se a responsabilidade dêsses funcionários pelas faitas, danos, avarias e quaisquer prejuízos que sofrerem os materiais sob sua guarda ou sujeitos ao seu exame. (22)

Criação do Departamento Federal de Compras e das Divisões de Material - (D.L. 2.206, de 20-5-1940) - A substituição da C.C.C. pelo D.F.C. e a criação dos órgãos de material nos Ministérios resultaram de cuidadosa análise das atividades da referida Comissão, realizada por dois técnicos da D.M. do D.A.S.P., através de observação in loco. (23)

Constataram êles as seguintes falhas, além de outras: injustificada demora nás aquisições; a ausência de contrôle estatístico de preços; acréscimo, nos preços dos fornecimentos, de $50 \%$ sôbre as cotações obtidas no comércio.

Evidenciou-se ainda que o fato de adquirir bem e por preço conveniente não era bastante para solucionar o problema, já que, não podendo o contrôle do órgão comprador ir além da verificação da existência de verba própria e suficiente, os pedidos não eram examinados sob o ponto de vista das reais

(20) Essa situação modifica-se, porém, em 1943, voltando o laboratório a integrar ○ órgão central de compras, já então o D.F.C. (D.L. 5.984), de 10-11-43).

(21) Mantidos no novo Estatuto (Arts. 194, IX e 28 da Lei 1.711-52) - Para pôr fim aos abusos na aplicação do material proibiu-se com a Circular S.P.R. n. ${ }^{2}$, de 23-1-41, o uso de papél oficial em correspondência e trabalhos particulares.

(22) V. arts. 227, § único, I e 262 da Lei 1.713-39; e Cap. IV e art. 214 da Lei $1.711-52$.

(23) E. M. n. ${ }^{\circ} 2.071$, de 26-10-39, 3. ${ }^{\circ}$ volume de Exposições de Motivos do D.A.S.P. 
necessidades dos serviços, nem se fiscalizava a aplicação do material adquirido, o que era fonte de aquisições supérfluas e de outras formas de desperdício.

Para sanar essa falha criaram-se nos Ministérios Divisões, Serviços e Secções de material, órgãos incumbidos de fazer as requisições de material, recebê-lo, distribuí-lo e fiscalizar-lhe o emprêgo, podendo, dessa forma, examinar a necessidade do material pedido e acompanhar-lhe a aplicação.

Como conseqüência, destinaram-se ainda êsses órgãos a proceder ao aproveitamento, cessão ou venda do material não utilizado; a organizar, de mcdo uniforme, os almoxarifados e depósitos; a levantar a estatística do material, estabelecer as pautas de consumo e os programas de compras; a fazer a escrituração relativa ao material; e a zelar pela observância da padronização.

Com a expedição do Decreto-lei 2.206, de 20-5-1940, procurou-se, pois, corrigir os defeitos do regime em vigor e cuidar da unidade do sistema pela articulação dos diversos órgãos .

Departamento Federal de Compras - A experiência com o funcionamento da Comissão Central de Compras levou o Govêrno a oferecer às operações do D.F.C. condições extremamente favoráveis.

Procurou-se eliminar, tanto quanto possível, as operações complicadas então em vigor, evitando-se a peregrinação do processo de compra pelo Tribunal de Contas e pelos órgãos do Ministério da Fazenda, resolvendo-se tudo dentro do próprio D.F.C., inclusive o pagamento.

Com êsse objetivo criaram-se uma Delegação do Tribunal de Contas e uma Contadoria Seccional junto ao Departamento e tornaram-se privativos dêste, para suas aquisições, o processamento, a liquidação e o pagamento das contas de fornecimento (Arts. 21, 27 e 28 do D.L. 2.206-40), simplificandose considerávelmente os trabalhos e permitindo-se a execução dos pagamentos em uma semana, sem qualquer intervenção dos credores. (24)

Estabeleceu-se o registro e distribuição automáticos das dotações destinadas à aquisição de material (Arts. 33 e 34); permitiu-se que, em casos excepcionais, a critério do Ministério da Fazenda, se prorrogue para o exercício seguinte - a fim de evitar o moroso processo de exercícios findos - a validade das verbas destinadas à compra de material cuja entrega não se possa fazer dentro do ano financeiro, evitando-se a ilegalidade dos recibos fictícios e os abusos que êstes propiciam (Art. 43).

Facultou-se ao D.F.C. a aquisição direta do material no estrangeiro para que o Govêrno pudesse, em casos especiais, defender-se das organizações e trustes exploradores das verbas orçamentárias (Arts. 30-32); impuseram-se prazos fatais ao Tribunal de Contas e sua delegação, sob pena de registro automático para as ordens de pagamento, possibilitando o pagamento das contas no prazo máximo de 15 dias; fixaram-se normas para os adiantamentos, visando a pôr côbro aos processos pouco recomendáveis então utilizados. (Arts. 45-48).

(24) Oscar Victorino Moreira, Ponto n. ${ }^{\circ} 3$ - p. 4 in fine. 
Para evitar impugnação do fornecimento por qualquer motivo de ordem comercial ou técnica, provocando a falta de confiança do comércio nos atos daquele Departamento, vedou-se ao Tribunal de Contas ou sua delegação apreciar o mérito do ato quanto à qualidade do material, escolha do preço e processo de compra (Art. 24); manteve-se o registro "a posteriori" para os contratos, ajustes, acôrdos, ou quaisquer atos relativos à aquisição de material. (25)

Regulamentou-se a concorrência e a coleta de preços, de modo geral, para tôda a Administração, em função do vulto da aquisição e não da dotação orçamentária conforme fôra critério do Código de Contabilidade Pública, estabelecendc-se, também nesse setor, situação privilegiada para o D.F.C. (Arts. 36-38).

Regimento do D.F.C. - Com o D. 5.848, de 22-6-40, foi aprovado o seu regimento, sendo nêle prevista a obrigatoriedade, por parte de todos os seus servidores, inclusive diretor geral, diretores e chefes de seção, de manter atualizada a relação de seus bens e haveres.

Regulamento das Aquisições - Com o D. 5.873, de 26-6-40, regulamentaram-se as aquisições de material, estabelecendo-se as normas de trabalho e as relações entre aquêle Departamento, os demais órgãos de material e os concorrentes.

Determinou-se a obediência, nas requisições de material, aos padrões, especificações e normas em vigor; facultou-se ao D.F.C. o estabelecimento de programas de compra de material padronizado, em grandes lotes, para fornecimento às repartições ou para ser estocado; regulamentou-se a questão da escolha de preço, prevalecendo sôbre a proposta do preço mínimo aquela que maiores vantagens trouxer aos cofres públicos.

Ao regulamentar as relações entre o D.F.C. e os demais órgãos de material( previu-se a rejeição, pelo Departamento, das requisições incompletas ou que não trouxerem declarado o orçamento provável de cada item requisitado e o cancelamento dos itens que não estiverem convenientemente classificados na dotação orçamentária própria ou que divergirem da padronização e especificações oficiais. (26)

Para evitar abusos nos pedidos de urgência por parte das repartições imprevidentes, regulamentou-se a questão de prazos para entrega de material; e definiram-se, ainda, as três operações diferentes de entrega, aceitação e recebimento de material. (27)

Quanto às relações entre concorrentes e o Departamento, procurou-se fugir ao formalismo do Código de Contabilidade da União (28) estabelecen-

(25) A Constituição de 34 fôra substituída pela de 37.

(26) Ver Portaria D.F.C. n. ${ }^{\circ}$, de 27-2-42 (D.O. de 2-3-42).

(27) Ver Portaria D.A.S.P. 165, de 19-6-43 (D.O. de 22) sôbre processamento das entregas e recebimentos de material.

(28) E. L. BERLINCK, A Reforma dos Serviços do Material, "Revista do Serviço Público" - Agôsto de 1940, p. 175. 
do-se que as concorrências públicas, administrativas e coletas de preços fôssem realizadas segundo instruções que o Diretor Geral do Departamento expedisse, o que não foi feito até a presente data, atribuindo o Prof. OsCAF VICTORINO MOREIRA a omissão à circunstância de haver sido aprovado por uma lei o Regulamento do Código de Contabilidade Pública (Lei 4.632, de 6-1-1923), o que the deu posição hieràrquicamente superior ao D. 5.873. (29)

Determinou-se ainda que as coletas de preços fôssem feitas por qualquer processo comercial, facilitando consideràvelmente a ação do órgão comprador.

Regimentos das Divisões e demais órgãos de material - Foram baixados então os regimentos dos órgãos de material dos Ministérios, (30) cuendo as Divisões do Material por finalidade a coordenação sistemática, a execução e a fiscalização das medidas de caráter administrativo, econômico e financeiro, relativas a material, no setor do respectivọ Ministério.

Cabe-lhes, pois, a execução de atribuições de grande relevância, desde a interferência na fase anterior à compra, para obstar aquisições supérfluas -função prevista na E.M. 2.071-39 e implícita em sua competência fixada com o art. $1 .^{\circ}$ do D.L. 2.206-40 - como após a aquisição, através do contrôl€ da redistribuição do material (cessões por empréstimo ou definitivas) e de sua venda, quando absolutamente inservível para o serviço público.

Estoque de material no D.F.C. - Com o D.L. 3.296, de 22-5-41, procura-se permitir, com a abertura do crédito especial de $\mathrm{Cr} \$ 2.000 .000,00$, a constituição no D.F.C. do estoque de material padronizado, de uso freqüente nas repartições. (31)

Conselho de Administração de Material - Em 31-7-43, com o D.L. 5.715, é criado o Conselho de Administração de Material (C.A.M.), órgão integrante do sistema de material.

Tendo por finalidade promover melhor coordenação e maior eficiência dos órgãos interessados na administração de material do serviço público civil federal, foi previsto seu funcionamento junto ao D.A.S.P.

Comunha-se de representantes dos seguintes órgãos:

a) D.M. do D.A.S.P. (seu Diretor);

b) D.F.C. (seu Diretor Geral e um dos diretores, designado pelo Diretor Geral);

c) Divisões do Material dos Ministérios (os respectivos diretores);

d) Instituto Nacional de Tecnologia (1 representante);

e) Associação Brasileira de Normas Técnicas (1 representante).

Foi prevista a convocação, para tomar parte em seus trabalhos, dos dirigentes ou representantes dos órgãos máximos das classes produtoras.

Determinou-se a reunião do Conselho ordinàriamente, 2 vêzes por semana, e extraordinàriamente, sempre que convocado pelo seu Persidente, o Diretor da D.M. do D.A.S.P.

(29) OSCAR Victorino MOReIRA, Apostilhas citadas - Ponto 3, 11.

(30) Decretos 6.586 , de $10-12-40,6.606$, de $18-12-40$ etc.

(31) Incluiu-se a dotação de $\operatorname{Cr} \$ 10.000 .000,00$, para o mesmo fim, no orçamento para o exercício de 1945 . 
Destinava-se o C.A.M. a corrigir, através de ação coordenadora, certas falhas ainda existentes no funcionamento do sistema de material.

Visava ainda o Govêrno, com a sua criação, a incrementar as suas boas relações com a indústria, cujas atividades tomavam grande desenvolvimento.

Em sua 1. a reunião, realizada em 23-8-43 (D.O. de 8-9-43, págs. 13.353), o seu presidente salientou a necessidade de dar a maior presteza aos seus trabalhos, já que, no setor material, rapidez significa resultado econômico.

Sendo o programa de trabalho muito vasto, estabeleceu-se o sistema de prioridade para os assuntos, sendo classificados como urgentes:

a) regimento das Divisões de Material dos Ministérios;

b) organização da forma de classificação orçamentária.

Ficou estabelecido ainda, como ponto de vista do Conselho, que o Diretor de cada D.M. deveria ser o relator da proposta orçamentária do seu Ministério, na parte relativa ao material.

Foi também lembrada a conveniência do estudo imediato da questão de inventários.

A atividade do Conselho foi intensa, realizando cêrca de 55 reuniões entre a data de sua criação (31-7-43) e 13-12-45 (2 dias antes passara a viger o D.L. 8.323-A, de 7-12-45, que transferiu o C.A.M. e a D.M. do D.A.S.P. para o D.F.C.).

Foram objeto de estudo do Conselho e da D.M. do D.A.S.P. os seguintes assuntos:

a) elaboração do "Indice de Classificação";

b) modificação da Instrução n. ${ }^{\circ}$, do D.A.S.P. (timbres e formatos de papéis oficiais) (D.O. de 21-12-43);

c) regulamentação da compra fora da sede do órgão comprador (D.O. de 21-12-43);

d) projeto de regulamentação do arrolamento e inventário do material (D.O. de 27-4-44 e de 21-8-45);

e) anteprojeto de decreto-lei sôbre a movimentação de contas, pelo D.F.C., no Banco do Brasil (D.O. de 27-4-44 e 25-7-44);

f) calendário de compras para o exercício de 1944, com alterações do anterior, a fim de remover dificuldades existentes em sua execução (D.O. de 4-1-44); 3.989);

g) instruções sôbre o Registro de Fornecedores (D.O. de 9-3-44, págs .

h) uniformização de pedido de impressos (D.O. de 12-6-44);

i) instruções sôbre recuperação, cessão e venda de material inservível (D.O. de 11-7-44 págs. 12.222);

1) modêlo de certificado para o registro de fornecedores do govêrno (D.O. de 23-2-44);

m) projeto de decreto-lei referente a requisição de transporte (D.O. de 1-2-44); 
n) normas para aceitação de material sujeito a exame técnico (D.O. de 1-2-44);

o) conservação de máquinas de escrever (D.O. de 10-3-45);

p) fornecimento de papel à imprensa; estimativa de preços nas requisições; observância da Portaria do D.A.S.P. n. ${ }^{\circ} 9$ sôbre requisição e aceitação de uniformes (D.O. de 9-5-46);

q) regimento da D.M. do M. da Justiça (D.O. de 19-8-44);

r) calendário de compras para 1946 (D.O. de 29-11-45);

s) projetos para criação da Divisão de Recuperação (D.O. de 29-11-45).

Registro dos fornecedores do Govêrno - Com o D.L. 204, de 17-1-44, e instituído no D.F.C., com caráter facultativo, êsse registro, que constituirá prova perante quaisquer repartições públicas, ainda que paraestatais, das condições gerais de capacidade prescritas por lei para a habilitação em concorrência e coletas de preços e que tem validade plena até o dia 31 de dezembro do ano em que fôr emitido. (32)

A causa primária dessa iniciativa governamental se enocntra na necessidade de evitar conluios entre fornecedores, prática fácil quando se conhecem com antecedência os. competidores. (33)

Com a existência dêsse cadastro, exige-se a apresentação de documentos apenas no ato do registro e dispensa-se a prestação de caução, o que permite que até o último momento se apresentem concorrentes, dificultando conchavos entre cs interessados.

A C.C.C. já lançara mão dêsse meio de moralização das concorrências, (34) com bons resultados.

Visou-se também, com a instituição do registro, a atingir o objetivo de uma sugestão da Associação Comercial do Rio de Janeiro no sentido de que fôsse criada uma carteira de identidade comprovante da condição de forn乞cedor do govêrno; o certificado de registro faz essa prova.

Reaproveitamento, venda e cessão dos resíduos, aparas, acondicionamentos e embalagens do material adquitido - Com o D. 14.655, de 2-2-44, regulamenta-se essa matéria, sendo prevista a expedição de instruções pelo D.A.S.P. e atribuindo-se, nos Ministérios, aos diretores das Divisões do Material, diretamente ou através dos demais órgãos de material, fazer executar o reaproveitamento dêsse material e autorizar sua cessão e venda, de acôrdo com as referidas instruções.

Aos dirigentes e chefes de repartições, serviços, seções, oficinas, 1aboratórios, almoxarifados e quaisquer outros órgãos do serviço público, atribuiu-se o encargo de zelar pelo cumprimento das medidas fixadas e tomar as providências cabíveis, no caso de ser observada alguma irregularidade.

(32) As instruções para inscrição no referido Registro foram publicadas no D.O. de 9-3-44, p. 3989 .

(33) Oscar Victorino Moreira; Apostilhas citadas - Ponto 5, p. 1.

(34) Idem. 
A cessão a entidades privadas só poderá ser feita a instituições filantrópicas e se restringe ao material de nenhum valor imediato para o serviço público. (35)

Compras nas fontes de produção - O recurso da compra de material nas fontes de produção já havia sido previsto em disposições anteriores: D. 19.587-31, Código de Contabilidade Pública e D.L. 2.206-40.

Todavia, a legislação oferecia dificuldades à realização das aquisições fora da sede do D.F.C., dando margem a pedidos de adiantamentos e dicpensas de concorrências. (36)

Expediu-se, então, o D.L. 6.292, de 24-2-1944 (D.O. de 26 que provocou, aliás, grande reação, já que êsse processo de compras nas fontes de produção constituía recurso eficaz contra a exploração e ganância dos intermediários. (37)

A exigência de cumprimento prévio de determinadas formalidades legais impediu que êsse decreto-lei atingisse plenamente os seus objetivos, tornandose necessárias providências posteriores. (38)

Todavia, dois benefícios trouxe êsse ato para o órgão comprador:

1..$^{\circ}$ permitiu que se adotasse o critério de fazer correr à conta da mesma subconsignação a despesa com o preço do material e tôdas as demais complementares (frete, seguro, armazenagem etc.) - o que só era praticado com relação às ocmpras realizadas, por concorrência, na praça do Rio (sede do D.F.C.), tendo em vista que nestes casos os preços propostos pelos fornecedores englobavam as despesas accessórias (art. 4. ${ }^{\circ}$ );

$2^{\circ}{ }^{\circ}$ possibilitou o cotejo de preços de material de acôrdo com a cláusula "C.I.F." Rio com propostas em moeda nacional, para entrega no local de aplicação. (Art. 2. ${ }^{\circ}$ )

Prioridade para importação de material durante o Estado de Guerra Visando a impedir a duplicidade de pedidos de prioridade para a importação de material destinado às repartições civis federais - prática usada por fornecedores inescrupulosos, que negociavam na praça o material excedente importado, (39) expediu-se o D.L. 6.357, de 21-3-44 (D.O. de 23), que determinou que as solicitações de licenças e prioridades para a importação do material cuja despesa corresse por dotação orçamentária ou crédito adicional se fizesse por intermédio do D.F.C., qualquer que fôsse a forma de aquisição ou o orgão comprador, ainda que se tratasse de aplicação de adiantamentos. (40)

(35) Instrução n. ${ }^{\circ}$ 10, aprovada pela Portaria D.A.S.P. n. ${ }^{\circ}$ 1083, de 24-11-44.

(36) E. M. 403, de 12-2-44-D.O. de 26, p. 3112.

(37) OSCAR Victorino MOREIRA, Apostilhas citadas - Ponto 4, p. 3.

(38) D. L. $7.584-45$.

(39) OSCAR Victorino Moreira, Apostilhas citadas, ponto 5, p. 3.

(40) Entre a legislação de emergência encontramos ainda o D.L. 4599 de 20-8-42, que autorizou o D.F.C. a requisitar aos fornecedores, durante o estado de guerra, o material necessário ao serviço público. 
Agência do D.F.C. em São Paulo - É criada com o D.L. 7.205, de 29-12-44 (D.O. de 3-1-45), na cidade de São Paulo, uma agência do Departamento Federal de Compras (A1. D.F.C.) com a finalidade de abastecer as repartições federais sediadas naquele Estado e, a critério do Departamento, nos Estados próximos.

Criam-se, com o mesmo ato, uma Delegação do Tribunal de Contas e uma Seccional da Contadoria Geral da República junto à mesma agência .

Centralização dos depósitos do Ministério da Fazenda - Com o D. 17.735 , de 2-2-45, incorporam-se ao Depósito da Divisão do Material do Ministério da Fazenda os almoxarifados ou depósitos de diversas repartições. localizadas no edifício-sede, (41) tornando-se competência privativa daquela D.M. a manutenção de depósitos de material no D. Federal (excetuando-se a Casa da Miseda).

Com êsse ato modificam-se ainda os têrmos do art. $1 .^{\circ}$ de seu regimento (D. 6.606-40), a fim de fixar-se sua jurisdição e competência.

Decreto-Lei 7.584, de 25-5-45 - Em sua constante preocupação com a eficiência do órgão comprador, procurou o Govêrno dar-lhe melhores condições de funcionamento, o que fêz através da expedição dêsse decreto-lei, que assume grande significação no desenvolvimento da administração de material, dado o admirável cunho revolucionário de suas inovações.

Definiram-se 3 tipos de aquisições:

I — às firmas sediadas na praça onde estiverem localizados o D.F.C. ou suas agências;

II - ainda no território nacional, porém em outras praças que não as previstas no item 1;

III - em fontes produtoras estrangeiras.

Procurou-se com essa regulamentação dar um caráter mais ativo ao órgão comprador, que poderá ir buscar nas fontes produtoras condições mais vantajosas para suas aquisições.

Fixou-se a aplicação de legislação diferente para os 3 tipos de aquisição, sendo que as previstas no item III obedecerão aos procedimentos comerciais comuns, independentemente de autorização superior.

Estabeleceu-se forma de contrôle, pelo Tribunal de Contas, da aplicação das dotações orçamentárias das unidades administrativas, nos casos de aquisições globais feitas em outros pontos do território nacional ou no estrangeiro (itens II e III).

Determinou-se a colocação no Banco do Brasil, à disposição do dirigente do D.F.C. ou suas agências, da totalidade dos créditos orçamentários e adicionais destinados à aquisição de material, pondo fim às dificuldades que os morosos suprimentos de fundos causavam ao órgão comprador.

(41) V. Instrução de Serviço D. G. n. ${ }^{\circ} 3$, de 15-2-45 (D.O. de 16), D. 22-363, de 27-12-46, art. 16 do D. 29.134 , de 15-1-51, Instrução de Serviço D. G. n. ${ }^{0} 1$, de 15-1-53 e art. $7 .^{\circ}$ do D. 38.673 , de 27-1-56. 
Fêz-se distinção entre a Conta de Fornecimento - a que pertencem também os resíduos passivos de exercícios encerrados, impedindo-se retardamento no pagamento das contas - e a Conta de Estoque, constituída de créditos orçamentários ou adicionais destinados à manutenção de estoques no D.F.C., sendo ambas movimentadas por meio de cheques nominativos, inclusive para aquisição nas praças estrangeiras.

Esta última conta atingia à época a $\mathrm{Cr} \$ 12.000 .000,00(\mathrm{Cr} \$ \ldots \ldots$ 2.000.000,00 provenientes do crédito especial aberto com o D.L. 3.296-41 mais Cr\$ $10.000 .000,00$ previstos no orçamento para 1945) e não se extinguiria, dada a sua natureza de crédito rotativo.

Previu-se a remessa de fundos para a Delegacia do Tesouro no estrangeiro, quando conveniente, em lugar de movimentação bancária.

Previu-se ainda o exame da despesa pelo Tribunal de Contas no exercício seguinte, nos casos em que o material adquirido na forma prevista nos itens II e III não cheguem ao destino no exercício financeiro em que esteja em vigor o crédito utilizado.

Estabeleceu-se prestação de contas especial para êsse tipo de aquisição (itens II e III), semelhante à utilizada na aplicação de adiantamentos.

Procurou-se simplificar o trabalho, com a inclusão da classificação da despesa uma única vez na fatura, no próprio texto; com a organização do Índice do Material, tarefa atribuída ao D.A.S.P.; com a classificação da despesa por êsse índice; com a previsão da devolução pelo Tribunal de Contas ao D.F.C. apenas da fatura cuja classificação da despesa seja impugnada, sem prejuizo das demais contidas na mesma relação.

Criou-se o Armazém de estoque do D.F.C., destinado a possibilitar que aquêle Departamento atenda ràpidamente aos pedidos das repartições, em se tratando de material de uso frequiente ou de material, de consumo ou permanente, de utilização certa.

Previu-se o levantamento de adiantamentos, condicionados às possibilidades da Conta de Estoque, para atender a compras de reduzido valor afastando os inconvenientes que surgiam com a falta de interêsse dos fornecedores - ou em casos especiais em que o D.F.C. verifique haver vantagem ou conveniência em pagar-se à vista .

Previu-se uma prestação de contas anual sôbre o movimento da conta de Estoque, a ser efetratada por uma comissão de três membros, um dos quais indicado pela Contadoria Geral da República.

Ficou, pois, o D.F.C., em face das disposições do D.L. 7.584, de 25-545, habilitado a fazer aquisições em condições muito mais vantajosas que qualquer portador de adiantamento, constituindo o ato um golpe contra a generalização dessa medida de exceção. (42)

O pleno funcionamento das funções de coordenação e de contrôle (exercidas através do C.A.M. e da D.M. do D.A.S.P.) constituía garantia suficiente contra abusos que as facilidades concedidas poderiam ensejar.

(42) Oscar Victorino Moreira, Apostilhas citadas, $4 .^{\circ}$ ponto, p. 17. 
4. ${ }^{\circ}$ Período - Com o D.L. 8.323-A, de 7-12-45, que reorganizou o D.A.S.P., inicia-se novo período, que perdura até os nossos dias e que se caracteriza por absoluta esterilidade, em chocante contraste com a extrema fecundidade da fase anterior.

Dois frutos daquela atividade intensa ainda se projetam sôbre o período que se inicia, mas, dadas as condições desfavoráveis do meio, não logram vingar.

São êles: a) o D. 21.826, de 5-9-46 (D.O. de 6), que, ao aprovar o regimento do D.A. do Ministério da Justiça - órgão central de sua administração geral - dispôs sôbre o regime da respectiva Divisão do Material, dando-lhe estrutura diferente, acrescendo-lhe uma Seção de Aplicação e Recuperação; e b) os Decretos-leis 9.633, de 22-8-46 e 9.824, de 10-9-46, que constituiram tentativa malograda de execução do arrolamento e inventário de material. (43)

Pertence a êste período a Lei 1.081 , de 13-4-1950, que, dispondo sôbre o uso de carros oficiais estabeleceu condições para sua aquisiçãc; trata-se, porém, de iniciativa do Legislativo (Projeto 255-47, do Deputado Lima Cavalcanti), que se valeu de um estudo feito pelo D.A.S.P. antes desta fase infecunda. (44)

A causa da esterilidade dêste período se encontra na transferência, efetuada com o citado Decreto-lei 8.323-A, da Divisão do Material do D.A.S.P. e do Conselho de Administração do Material - que funcionava junto àquele Departamento - para o D.F.C.

Essa transferência, fruto, por certo, de mau assessoramento, importou na desarticulação de todo o sistema de administração de material - laboriosamente construído, como se demonstrou - com graves. consequiências para os cofres públicos.

\section{CONCLUSÃO}

Os órgãos de material, dada a unificação do sistema de administração de material, foram criados para funcionar em regime de íntima coordenação, sob a direção do Presidente da República, única autoridade eqüidistante de tôdas as peças do organismo.

Todavia, desde a expedição do D.L. 8.323-A, essa direção tem sido deficiente, dada a ausência de um estado-maior qualificado que auxilie o Chefe do Executivo nesse setor especializado.

Enquanto se reconhecia o D.A.S.P., com êsse ato, competência para o estudo e a orientação de problemas de administração geral (pessoal, orça-

(43) Ver ata das $18 .^{a} 27 .^{a}$ e $46 .^{a}$ reuniões do C.A.M. (D.O. de $27-4-44,19-8-44$ e 21-8-45).

(44) Regulamentada, por imperativo legal (art. 16), pelo Decreto 28.425 , de 27-7-50. 
mento, edifícios públicos, documentação, (45) transferia-se sua Divisão do Material para o D.F.C., negando-se àquele Departamento, apesar de sua comprovada eficiência na matéria, qualquer participação em um dos setores mais importantes dessa administração.

Enqunto se criava junto ao D.A.S.P. um Conselho de Administração com a finalidade de promover a melhor coordenação e maior eficiência dos órgãos de organização, de pessoal, de orçamento e os relativos à construção de edifícios públicos, transferia-se o Conselho de Administração do Material para a repartição compradora, abandonando-se os órgãos de material à própria sorte e - o que acentua a gravidade da iniciativa - logo após a concessão de um regime de extrema facilidade ao funcionamento do Departamento Federal de Compras. (46)

Oportunas as considerações de NORMan M. Pearson, (47) ao demonstrar a necessidade de existência de um órgão de estado-maior administrativo.

" $€$ possível sustentar-se que a coordenação pode ser assegurada por meio de comissões interdepartamentais ou simplesmente por meio de entendimento entre os departamentos interessados num assunto particular afeto a mais de um dêles.

Tais conferências ou entendimentos interdepartamentais, entretanto, nem sempre conseguem a coordenação ou resolvem divergências porque as partes interessadas possuem igual autoridade. Por conseguinte, deve haver recurso a uma autoridade administrativa superior, como o Presidente. Tendo-se em vista o número atual de repartições federais" (as condições são as mesmas no Brasil) "não é possível que tais recursos sejam, de maneira diligente, tratados pessoalmente pelo Presidente. A repartição de estado-maior, sob imediata supervisão do chefe executivo, teria o "manto de autoridade" necessário para resolver as divergências de modo objetivo e de acôrdo com as diretrizes do Presidente."

Em consequiência da falha apontada, têm faltado à administração de material (48) programa de ação (previsão ou planejamento), organização racional (apresenta hoje estrutura anômala e recursos humanos, materiais e financeiros inadequados), coordenação e contrôle (a enxertia do C.A.M. e da D.M. do D.A.S.P. no D.F.C. não vingou, dada a falta da necessáina afinidade).

Não se pode, assim, estranhar que as condições atuais de funcionamento do Departamento Federal de Compras e dos demais órgãos de material sejam

(45) Leia-se o novo regimento, aprovado com o D. 20.489, de 24-1-46.

(46) A Lei 830-49 e suas interpretações têm limitado essas facilidades.

(47) "Um Estado-Maior Administrativo para Auxiliar o Presidente" - Revista do Serviço Público - Julho de 1946.

(48) Segundo o mestre HENRI FAYOL, a administração eficiente não pode prescindir de previsão, organização, coordenação e contrôle - Administração Industrial e Geral, págs. 17. 
grandemente prejudiciais aos interêsses públicos (49) e que estejam a exigir providências urgentes do Govêrno. (50).

E a explicação para o fenômeno da sobrevivência - apesar do conhecido desejo de auto-suficiência das repartições - de um sistema que se tem revelado ineficiente, parece que pode ser encontrada na freqüência com que se recorre aos adiantamentos - medida excepcional já vulgarizada — ou se procura a autonomia administrativa. (51)

Exemplo marcante de busca da autonomia em razão da ineficiência cios órgãos de adninistração geral encontramos no projeto de criação do Instituto Nacional de Assistência a Menores. (52)

Pode-se estranhar que os governos que se têm sucedido após 1945 não tenham, em sua constante preocupação com a compressão de despesas, explorado um setor que oferece, indiscutivelmente, enormes possibilidades de economia: parece-me, porém, que ainda aqui se pode atribuir a responsabilidade, em grande parte, à falta de assessoramento adequado.

Tal não aconteceu com c atual Governador do Estado de São Paulo que, não desprezando qualquer possível fonte de recursos para a sua obra de recuperação financeira daquela unidade da federação - já agora esplêndida realidade - tem tirado os maiores proveitos do regime da compra centralizada, ob̆tendo economia de muitos milhões de cruzeiros. (53)

O crédito de que goza aquêle Govêrno, em virtude da rigorosa honestidade das concorrências e da presteza e segurança dos pagamentos, faculta aos fornecedores descontar o respectivo título de crédito em qualquer banco da praça, inclusive os estrangeiros.

$\mathrm{E}$, enquanto na esfera federal o estoque do órgão comprador acha-se em liquidação em virtude de decisão do Ministério da Fazenda que, fundamentada em interpretação do D.L. 9.813, de 9-9-46 (54), pôs fim ao crédito rotativo destinado à consttiuição de estoque de material no D.F.C., aquêle Governador valoriza consideràvelmente o crédito rotativo da respectiva repartição compradora.

Êsse problema da extinção do armazém de estoque do Departamento Federal de Compras, é, porém, apenas uma das inúmeras questões que estão a clamar por atenção das autoridades competentes.

(49) Oscar Victorino Moreira, Redução do Custo dos Serviços de Material (1950).

(50) Já salientou JOHN R. SIMPSON (op. cit., págs. 24) que a compra centralizada exige vigilância contínua para evitar que degenere na pior forma de burocracia.

(51) Leis 592, de 23-12-48, 830, de 23-9-49 (Art. 66) etc.

(52) Apesar do tom de ressentimento que marca a obra, reduzindo-lhe o valo: documentário, o livro Sangú, Corrupção e Vergonha do ex-diretor do S.A.M., PAUlo NOGUEIRA FILHO, constitui um libelo contra a administração geral centralizada ineficiente.

"O Globo", de 23-2-56 e "Manchete" de 13-10-56.

(54)

OSCAR Victorino MOREIRA, Apostilhas citadas, ponto 8, p. 6 (1956). 
São algumas delas:

a) inventário do material;

b) recuperação de material (dever-se-ia evitar a alienação, por vêzes a preço de sucata, de guindastes, locomotivas etc. - de custo atual elevadíssimo - sem que se procurasse, com empenho, a sua recuperação);

c) consêrto de material, que constitui hoje fonte de evasão de rendas e propicia tôda sorte de fraudes;

d) enorme atraso no fornecimento de impressos pelo Departamento de Imprensa Nacional (as causas reais devem ser procuradas, não sendo de aceitar-se de pronto as sempre alegadas razões de falta de pessoal etc.);

e) falta de aparelhamento das repartições aduaneiras, uma das causas da continuidade do contrabando;

f) índice do material para classificação da despesa;

g) exame prévio pelas Divisões de Material das propostas orçamentárias, na parte relativa a material;

h) centralização de determinadas dotações nas D.M., de forma, porém, que se garantam os reais interêsses das repartições;

i) a realização por êsses órgãos de material dos objetivos visados com a sua criação (parece que não há exagêro em dizer-se que hoje, executando apenas um mínimo das atribuições previstas em seus regimentos, são as Divisões de Material órgãos excrescentes na estrutura administrativa brasileira);

j) criação de órgãos centrais de material nos Estados;

1) ineficiência do atual sistema de tomada de contas dos responsáveis por bens públicos (mera aprovação de conta corrente, em que as saídas escondem, por vêzes, transferência de guarda de bens a outros setores; (55)

m) necessidade de maior divulgação sôbre a administração de material, em "rotinas" sucintas e objetivas;

n) regulamentação do processo de coleta de preços;

o) a dualidade de pesquisa de preços (pelo D.F.C. e pela repartição que tem que indicar o preço provável do item requisitado);

p) interpretação do art. 141 da Lei $830-49$, tendo em vista os interêsses da administração de material;

q) armazenagem; (56)

(55) Dizemos com Agnello UchôA BITTENCOURT ("Notas sôbre o Tribunal de Contas da União" - Ensaios de Adiministração n. ${ }^{\circ} 3$ - D.A.S.P. 1955) que urge fazer uma revisão legislativa sôbre o Tribunal de Contas, de modo a dar-lhe maior celeridade e eficácia.

(56) Há alguns estudos sôbre o assunto: "Depósitos Centrais no Sistema de Material" - OSCAR VICTORINo MOREIRA (1947) e "Despesas de Fornecimentos pelo Departamento Federal de Compras e Subsídios à Reforma Administrativa" - GIL SOBRAL PINTO. 
r) serviços de limpeza e conservação das repartições por emprêsas particulares (parece que não se justifica que havendo nas repartições uma classe de servidores a que compete a execução dêsses serviços (57 se majore extremamente o custeio das mesmas (58) com a atribuição dessa tarefa a elementos stranhos);

s) a vulgarização dos adiantamentos; e

t) atualização da padronização do material.

Muitas delas, porém, envolvem outros setores de atividades institucionais (pessoal, orçamento etc.) e para solução satisfatória deverão ser estudadas por um departamento de administração geral, cujo dirigente estará capacitado para o pronunciamento final junto à chefia executiva máxima, já que é o orientador e coordenador de suas atividades internas, que devem incluir um setor especializado em material.

(57) Leiam-se as instruç,es para as provas •de habilitação para preenchimento de funções da série funcional de Servente (D.O. de 10-5-40, págs. 8.513; D.O. de 15-9-43, págs. $13.777-$ P.H. $405 ;$ O.O. de $8-8-44$, págs. $13.939-$ P.H. $913 ; D . O$. de 22-9-44, págs. 16.526 - P.H., 551 e D.O. de 27-10-53, p. 18.253).

(58) A Administração do Edifício da Fazenda conta com Cr $\$ 1.000 .000,00$ para o exercício de 1957 na Consig. 1.5.00 - Serviços de Terceiros; Subconsignação 1.5.05 Serviço de asseio e higiene; taxas de água, esgôto e lixo. 